\title{
ORTA GELİR TUZAĞI: YAPISAL KIRILMALAR ALTINDA E7 ÜLKELERİ İÇİN AMPİRIKK BİR İNCELEME
}

\author{
Muhammed TIRAŞOĞLU* \\ Fatih KARASAÇ**
}

\begin{abstract}
Öz
İktisat literatürünün yeni ve ilgi çeken konularından biri orta gelir tuzağıdır. Orta gelir tuzağı, genel olarak orta gelirli ülkelerin yavaş büyüme performansı sergileyerek belirli gelir seviyesinde sıkışması ve yüksek gelir grubuna geçememesi olarak tanımlanabilir. Bu çalışmanın amacı, gelişmekte olan ülkeler arasında önemli yere sahip E7 (Gelişen 7) ülkelerinin orta gelir tuzağında olup olmadığını araştırmaktır. Bu kapsamda Robertson ve Ye (2013) yaklaşımı dikkate alınmıştır. Ampirik analizler tek ve iki yapısal kırılmalı birim kök testleri kullanılarak yapılmıștır. Yapılan analizler sonucunda E7 ülke grubunu olușturan ülkelerden Endonezya, Meksika ve Rusya'nın orta gelir tuzağında olduğu yönünde kanıtlara ulaşılmıştır. Brezilya, Çin, Hindistan ve Türkiye'nin ise genel olarak orta gelir tuzağında olmadığı bulgularına ulaşılmıştır.
\end{abstract}

Anahtar Kelimeler: Orta Gelir Tuzağı, E7 Ülkeleri, Yapısal Kırılmalı Birim Kök Testleri.

\section{Middle-Income Trap: An Empirical Analysis for E7 Countries Under Structural Breaks}

\begin{abstract}
One of the new and interesting topics of the economic literature is middleincome trap. Middle-income trap can be generally defined as middle-income countries showing a slow growth performance, jamming at a certain level of income and can not pass to high income groups. The aim of this study is to investigate whether the E7 (Emerging 7) countries, which have an important place among the developing countries, are in middle-income trap. In this context, Robertson and Ye (2013) approach has been taken into consideration. Empirical analyzes were performed using single and two structural breaks unit root tests.
\end{abstract}

\footnotetext{
* Dr. Öğr. Üyesi, Kırklareli Üniversitesi, İktisadi ve İdari Bilimler Fakültesi, muhammedtirasoglu@klu.edu.tr

** Arş. Gör., Kırklareli Üniversitesi, İktisadi ve İdari Bilimler Fakültesi, fatihkarasac@klu.edu.tr
}

DOI: $10.17550 /$ akademikincelemeler.430713

Geliş T./Received D.: 04.06.2018 Kabul T./Accepted D.: 19.08.2018 
As a result of the analysis, evidence has been obtained that Indonesia, Mexico and Russia that member of E-7 groups, are in the middle-income trap. Brazil, China, India and Turkey are not generally in the middle-income trap.

Keywords: Middle-Income Trap, E7 Countries, Structural Breaks Unit Root Tests.

\section{Giriş}

Kalkınma ekonomisi literatüründe, çok sayıda yoksul ülkenin neden orta gelirli ${ }^{1}$ olmadıklarını ve neden yoksulluğun nesilden nesile sürdüğünü açıklamak için uzun yıllar boyunca 'yoksulluk tuzağı' kavramı yaygın olarak kullanılmıştır. Buna karşılık, orta gelir tuzağı kavramı, yaklaşık on yıl öncesine kadar kullanılmamaktaydı. Çünkü bu, gelişmekte olan ülkelerin, yoksulluk engelini aştıklarında, ekonomilerinin zamanla daha yüksek gelir seviyelerine doğru sürekli olarak yükseleceği yönündeki popüler inançtan kaynaklanmaktaydı (Zeng \& Fang, 2014, s. 1017).

Bununla birlikte, orta gelir grubundaki ülkelerin çoğunun gelişme aşamaları, sürekli olamamış ve birçok orta gelirli ülkenin kişi başına düşen GSYİH'si, ancak orta gelir düzeyinde yukarı ve aşağı yönde hareket etmiş ve asla yüksek gelir seviyesine çlkamamıștır. Bu durumda olan ve orta gelir düzeyindeki ülkelerin yüksek gelir seviyesine ulaşamaması orta gelir tuzağı kavramının ortaya çıkmasına neden olmuştur.

Özellikle son on yılda 'orta gelir tuzağı' konusunun iktisat literatüründe yoğun bir șeklide ele alındığı görülmektedir. Bunda orta gelir düzeyindeki ülkelerin küresel ekonominin bütünündeki

\footnotetext{
${ }^{1}$ Mevcut durumda, ülkelerin gelişmişlik düzeyleri üç gruba ayrılmaktadır. Dünya Bankası Atlas Metodu yöntemiyle yapılan 2015 yılı için hesaplamalar neticesinde, kişi başına düşen milli geliri 1025\$'dan az olan ülkeler düşük gelir seviyesinde, $1025 \$$ ile $12475 \$$ aralığında olan ülkeler orta gelir seviyesinde $(1045 \$$ ile $4035 \$$ aralığındakiler alt orta, $4036 \$ 1$ ile $12475 \$$ aralığındakiler üst orta gelir) ve $12476 \$$ 'dan yüksek seviyede olan ülkeler ise yüksek gelirli ülkelerdir (Dünya Bankası).
} 
önemi etkili olmuştur. Çünkü bu ülkelerin herhangi birinde yaşanacak ekonomik bozulma, dünya ekonomisini de olumsuz etkileyebilecektir. Bundan dolayı orta gelir tuzağı ile ilgili ele alınan çalışmalar daha çok orta gelir düzeyindeki ülkeler etrafında kümelenmiștir.

Ele alınan bu çalışmada orta gelir düzeyinde yer alan E7 ülkelerinin orta gelir tuzağında olup olmadığını Robertson ve Ye'nin (2013) geliştirdiği yaklaşım kullanılarak analiz edilecektir. $\mathrm{Bu}$ amaçla, çalışmanın ilk bölümünde orta gelir tuzağı kavramının tanımı ve teorik temelleri, ikinci bölümünde ampirik çalışmalar ile ilgili literatür incelemesi, üçüncü bölümde çalışma kapsamında uygulanacak ekonometrik metodolojiye yer verilecektir. Son bölümde ise ele alınan uygulamanın bulguları aktarılacak ve E7 ülkelerinin orta gelir tuzağında olup olmaması bakımından değerlendirmelerde bulunulacaktır.

\section{Orta Gelir Tuzağının Tanımı ve Teorisi}

Orta gelir tuzağı (OGT), hem bilimsel hem de bilimsel olmayan literatürde sıklıkla kullanılmaya bașlamıștır. Kavramsal olarak yeni bir kavram olan bu olgu, ilk kez 2007 yılında, Dünya Bankasının bir raporu olan “Bir Doğu Asya Rönesans'ı: Ekonomik Büyüme için Fikirler" adlı çalışmada Gill ve Kharas (2007) tarafından belirtilmiştir. Söz konusu raporda, orta gelir seviyesine ulaşmış bazı ülkelerin, düşük gelir grubundaki ülkeler ile ücret bakımından rekabet edemedikleri, yüksek gelir grubundaki ülkeler karşısında ise inovasyona yönelik büyüme stratejileri gerçekleştiremediklerinden, düşük büyüme performansı gerçekleștirmek suretiyle orta gelir tuzağına yakalandıkları vurgulanmıştır (Gill \& Kharas, 2007, ss. 17-18).

OGT’nin tanımı konusunda fikir birliği olmasa da, genel olarak, düşük gelirli ülkelerin hızlı bir büyüme gerçekleștirdikten sonra belirli bir gelir seviyesinde durağanlaşması ve uzun yıllar bu gelir seviyesinde kalması şeklinde yapılmaktadır (Tho, 2013, s. 3; Felipe \& Kumar, 2012, s. 6; Jankowska, v.dğr., 2012, s. 1). 
OGT’ye ilișkin farklı teorik yaklașımlar öne sürülmüștür. İncelenen teorik yaklaşımlar genelde büyüme ve kalkınma ekonomisi teorilerine dayandırılmaktadır. $\mathrm{Bu}$ teorilerden ilki Solow-Swan büyüme modelidir. Buna göre, kişi başına düşen çıktı miktarının dengede olduğu yani arttırılamadığı durağan durum dengesi, OGT olarak nitelendirilmektedir (Yeldan, 2012, s. 33).

OGT ile bağdaştırılan teorik yaklaşımlardan bir diğeri ise Lewis Sinırsız Arz Model'idir (Eichengreen, 2012; Agénor \& Canuto, 2015). Bu modelde, Lewis dönüm noktasının birçok ülke için orta gelir düzeyinde oluştuğu vurgulanmıștır (Gill \& Kharas, 2015, s. 12). $\mathrm{Bu}$ çerçevede, kalkınmanın ilk aşamalarında tarıma dayalı düşük gelirli ekonomiler, dışarıdan ithal ettikleri teknoloji ve ucuz emek girdisiyle maliyeti az olan ürünler üretmek koşuluyla, uluslararası pazarlarda rekabet gücü elde ederler. Kalkınmanın bu aşamasından sonra düşük gelirli tarım sektöründen verimli modern sektörlere geçen emek sayesinde bu ekonomilerde verimlilik artıșı sağlanmıștır. Orta gelir düzeyi olarak nitelendirilen bu aşamada, kırsal kesimdeki emek arzının düşmesiyle, verimlilik artışıyla sağlanan büyüme artık sürdürülememekte ve yavaşlamaya başlamaktadır (Agenor, 2012, ss. 2-3).

OGT’yi açıklayan diğer bir yaklaşımda ise Tho (2013) ekonominin gelişim aşamaları yardımıyla orta gelir tuzağını teorik olarak açıklamaya çalışmıştır. Buna göre ekonominin gelişim süreci üç aşamadan oluşmaktadır. Bahsedilen aşamalar Şekil 1'de gösterilmektedir. Şekilde A ile B noktaları arası, yoksulluk tuzağında olan az gelişmiş ülkeleri temsil etmekte, B ile C arası, yoksulluk tuzağından kurtulan ve kalkınmanın ilk aşamasını gerçekleştiren tarımdan sanayiye doğru yönelen orta gelirli ülkeleri göstermektedir. C ile D noktaları arası ise, sürdürülebilir büyüme performansı gerçekleștiren gelişmiş ülkeleri göstermektedir. Buna göre, yoksulluk tuzağından kurtulan ülkelerin bulunduğu B ile C noktaları arasındaki ülkeler tarım ağırlıklı bir ekonomik yapıdan sanayi ve hizmete dayalı bir ekonomik yapıya geçişi sağlamışlardır. Bu ülkeler orta gelir düzeyi olan C noktasına eristiklerinde, önceki dönemde sağladıkları büyüme performanslarını sağlamaları artık zorlaşmıştır. Düşük 
büyüme dönemine giren bu ülkeler C ve E noktaları arasına sıkışarak orta gelir tuzağına yakalanmışlardır (Tho, 2013, ss. 4-5).

Şekil 1: Ekonominin Gelişme Aşamaları ve OGT

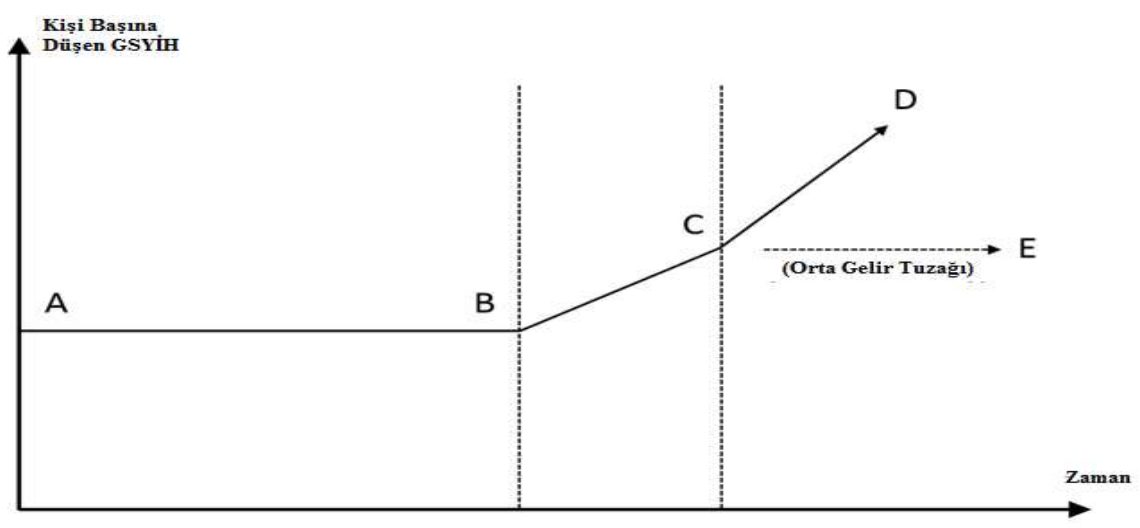

Kaynak: Tho, 2013, s. 4.

En nihayetinde teorilerin temel argümanları şu şekildedir; ülkeler, orta gelir seviyesine ulaşmak için tarım ağırlıklı ekonomiden düşük maliyetli imalata dayanan emek yoğun üretime geçmektedirler. Bu sayede bu ülkeler uluslararası düzeyde rekabet edebilirler. Böylece gelişmekte olan bu ülkeler, işçilerin tarım sektöründen imalat sektörüne transfer olmalarıyla ithal teknolojiye dayanan stratejiler ile üretkenlik kazançları sağlamaktadırlar. Fakat eninde sonunda vasıfsız emek transferi bitecek ya da emek emici aktiviteler zirveye ulaşacaktır. Sonrasında kentsel alanlarda imalat sektöründe reel ücretler hızlı bir şekilde artacak ya da piyasa payını kaybedecektir ve ithal edilen yabancı teknolojiden elde edilen kazançlar hızlı bir şekilde azalacaktır. Sonuç olarak sektörler arası tahsisten ve teknolojik ilerlemeden elde edilen üretkenlik büyümesinin sonuna gelinecek; uluslararası rekabette geriye düşülecek ve üretim ve büyüme azalacaktır. Bu yüzden ülkeler, üst gelir seviyesine geçememekte ve orta gelir tuzağına yakalanmaktadırlar (Agenor \& Canuto, 2015, s. 643). 


\section{Ampirik Çalışmalara İlişkin Literatür İncelemesi}

OGT’ye yönelik yapılan ampirik çalışmalarda göze çarpan en önemli nokta ülkelerin gelirleri konusunda elde edilen eşik değerlerin belirlenmesi konusudur. Çalışmalar genellikle nispi veya mutlak eşik değerler belirlenerek yapılmaktadır. Zira belirlenen bu eşik değerler OGT'nin kolayca belirlenmesini de sağlamaktadır. Buna göre en çok kullanılan mutlak gelir eşiği, Dünya Bankası tarafından belirlenen Atlas Metodudur. Atlas Metodunun yanı sıra yazarların kendi hesaplama yöntemleri neticesinde belirledikleri mutlak orta gelir eşikleri de bulunmaktadır (Eichengreen \& Shin, 2012; Felipe, 2012; Aiyar, v.dğr., 2013). Örneğin Felipe ve Kumar (2012), 1950-2010 yıllarını kapsayan çalışmalarında, yapmış oldukları hesaplamalar ile 124 ülkeyi dört farklı gelir grubuna ayırmışlardır. Buna göre 2000 \$'dan daha az kişi başı gelire ait ülkeler düşük; 2000\$-7250\$ arasındakiler alt orta; $2000 \$-11750$ 'a sahip ülkeler üst orta; 11750 \$'dan yüksek kişi başına düşen geliri olan ülkeler ise yüksek gelir düzeyindeki ülkelerdir. Yapılan bu çalışmanın sonuçlarına göre ülkelerden 40'ı düşük; 38'i alt orta; 14'ü üst orta ve 32'si yüksek gelirli ülkedir.

Diğer taraftan nispi eșik değerlerinde ise, genellikle, ABD ya da başka bir gelişmiş ülkenin kişi başına düşen gelirine ne oranda yaklaştığını gösteren değerleri ifade eder (Woo, 2012; Robertson \& Ye, 2015; Bulman, v.dğr., 2014; Im \& Rosenblatt, 2013). Örneğin, Woo (2012), OGT'yi belirlemek için Yakalama Endeksini oluşturmuştur. Buna göre, Maddison'un (2010) hazırlamış olduğu Maddison Project veri tabanını kullanarak ülkelerin kişi başına düşen gelirlerini ABD'nin kişi başına düşen gelirine oranlama suretiyle ülkeleri yüksek, orta ve düşük gelirli ülkeler şeklinde kategorize etmiştir. Söz konusu çalışmada, ele alınan ülkelerin kişi başına düşen gelirleri belirlenen endeks doğrultusunda ABD’nin kişi başına düșen gelirinin \%55'inde fazla olan ülkeler yüksek gelirli, \%55'i ile \%20'si arasında olan ülkeler orta gelirli ve \%20'sinden düşük olan ülkeler düşük gelirli ülkeler olarak belirlenmiştir. Çalışmanın sonuçlarına göre Batı Avrupa ülkeleri yüksek gelirli ülkeler, Sahra Altı ülkeler, ise düşük gelirli ülkelerdir. 
Güney Amerika ülkeleri ile Doğu Asya ülkeleri ise orta gelir tuzağında oldukları belirtilmiştir (Woo, 2012, ss. 315-317).

Mutlak ve nipi eşik değerlerin belirlenmesi ile birlikte çeşitli regresyon denklemleri, nedensellik analizleri gibi ekonometrik yöntemler kullanılarak OGT'nin belirlenmesine yönelik çalışmalar yoğun bir şekilde görülmeye başlamıştır.

OGT’nin ampirik olarak incelenmesi açısında öncü çalışma niteliği taşıyan Robertson ve Ye'nin (2013) çalışmasında, nispi eşik değerler ile uygun bir şekilde OGT'nin zaman serisi tanımı geliştirilmiştir. Buna göre herhangi bir A ülkesinin OGT'de olup olmadığı incelemek için bu ülkenin GSYH'nın doğal logaritmasından ABD gibi istikrarlı bir büyüme oranına sahip gelişmiş bir ülkenin GSYH'nın doğal logaritması çıarılmakta ve ortaya çıkan yeni seriler ile durağanlık analizi yapılmaktadır. Durağanlık analizinin uygulanacağ olarak şu şekilde gösterilmektedir:

$$
x_{t}=\ln G S Y H_{A, t}-\ln G S Y H_{A B D, t}
$$

Buna göre, $x_{t}$ serisi durağan ise A ülkesi OGT'dir ve gelişmiş ülkeleri GSYH açısından yakalama eğiliminde değildir.

Bu kapsamda, Robertson ve Ye (2013), 1950-2010 yılları için 46 orta gelir düzeyindeki ülkeyi incelediği çalışmasında hangi ülkelerin OGT'de olduğunu birim kök testleri aracılığıyla test etmişlerdir. İlgili çalışmada yapısal kırılmaları dikkate almayan Dickey Fuller'ın (1981) geliștirdiği birim kök testi ile yapısal kırılmaları dikkate alan Zivot ve Andrews (1992) ve Lumsdaine ve Papell'in (1997) geliştirmiş oldukları birim kök testleri kullanılmıştır. Yapılan birim kök testlerinin sonuçlarına göre, 46 ülkeden 23'ü en az bir birim kök testine göre OGT'de, Türkiye yapısal kırılmaları dikkate alan testlerde OGT'de değilken, yapısal kırılmaları dikkate alan birim kök testine göre OGT'dir.

Eichgreen vd. (2012), 1957-2007 dönemi için 45 ülkeyi ele aldıkları çalışmalarında, 1957-2007 dönemi için Chow testi ve 
Probit testleri ile bu ülkelerin OGT'de olup olmadıklarını test etmişlerdir. Ele alınan bu çalışmada OGT'ye düşen ülkelerin kişi başına düşen gelir seviyelerinin $10000 \$-11000 \$$ ile $15.000 \$-$ $16000 \$$ düzeylerinde olabileceğini belirtmişlerdir. Buna göre demokratikleșme ile büyüme yavaşlaması arasında anlamlı bir ilişki bulunmuştur. Bunun yanı sıra orta gelir düzeyine ulaşan ülkelerin OGT'den çıkması için beşeri sermayeye önem vermeleri gerektiğini vurgulamış ve yüksek teknolojili ürünlerin ihracat içindeki payının arttırılması gerektiğinin altı çizilmiştir.

Diğer bir çalışmada Aiyar vd. (2013) çoğunlukla Latin Amerika ve Asya ülkelerini içeren 138 ülkeyi ele aldıkları çalışmalarında 1955-2009 yıllarını 11 döneme ayırmış ve bu ülkeler için OGT'nin belirleyicilerini Probit Regresyonu, Bayesian ve Ağırlıklandırılmış En Küçük Kareler Yöntemi kullanarak araştırmışlardır. Kurumların önemi, demografik ve altyapı faktörlerinin yanı sıra ticaret alt yapısının, ampirik sonuçlarını ülkelere özel olarak detaylı bir şekilde sunmuşlardır. Diğer taraftan, OGT'nin sebeplerini, gayri safi sermaye oranlarındaki azalmalar ve ihracata konu olan ürün çeșitliliğinin azlığı şeklinde sıralamışlarıdır.

Egawa'nın (2013) Malezya, Çin ve Tayland'ı 1990-2011 dönemleri için incelediği çalışmasında gelir dağılımı eşitsizliğinin OGT'ye sebep olup olmadığını Regresyon Analizi ve Duyarlılık Analizi kullanarak araştırmışlardır. Buna göre, gelir eşitsizliklerinin büyüme oranlarını negatif etkilediğini ve OGT'nin sebeplerinden biri olduğu sonucuna varmıștır.

Diğer bir çalışmada Bozkurt vd. (2014) 1971-2012 dönemlerini kapsayan araştırmalarında yakınsama ve ARDL analizi kullanılarak Türkiye'nin OGT'ye yakalanıp yakalanmadıklarını incelemişlerdir. Buna göre, Türkiye'nin yüksek gelirli ülkelere yakınsadığı ve OGT'den kurtulması için eğitim sisteminin teknoloji odaklı olmalı ve sanayileşmenin önündeki risklerin ortadan kaldırılması gerektiği vurgulamışlardır. 
Yıldız ve Bayraktar'ın (2017) çalışmasında, Türkiye'nin de yer aldığı kırılgan sekizli ülkelerin OGT'ye düşme ihtimallerini gelişmiş ülkeler ile karşılaştırmalı olarak analiz etmişlerdir. Buna göre, orta gelir tuzağına düşme ihtimali en az olan ülke Rusya iken bu ülkeyi Hindistan, Şili ve Türkiye izlemektedir. Çalışmada kullanılan göstergeler ışığında en kötü performans sergileyen ve orta gelir tuzağına düşme ihtimalinin en yüksek olduğu ülke ise Güney Afrika olduğu tespit edilmiştir.

Diğer bir çalışmada ise, Dalgıç vd. (2014), Türkiye'yi de içine alan 56 orta gelirli ülkeyi OGT'den kurtularak yüksek gelirli konuma geçmesi için hangi faktörlerin etkili olduğunu 1990-2013 dönemini kapsayacak şekilde Probit Modeli kullanılarak analiz etmişlerdir. Yapılan analizin sonuçlarına göre, beşeri sermaye ve teknolojideki gelişme ile birlikte kurumsal kalitenin arttırılması yüksek gelirli konuma geçmede önemli faktörler olarak değerlendirmişlerdir.

Koçak ve Bulut'un (2014) ele aldıkları çalışmada, Robertson ve Ye'nin (2013) yaklaşımı ile birim kök testler aracılığıyla Türkiye'nin orta gelir tuzağında olup olmadığı analiz edilmiştir. Buna göre, Türkiye ve ABD'nin 1950-2010 yılları için 2005 yılı sabit fiyatları kullanılarak satın alma gücü paritesi esaslı GSYH serilerinin logaritması kullanılmıştır. Yapılan birim kök testlerinin sonuçlarına göre, Türkiye, ABD ile olan gelir farkını kapatma eğilimi göstermiş ve Türkiye'nin OGT'de olmadığı sonucuna varılmıştır.

Robertson ve Ye (2013) yaklaşımını dikkate alan bir diğer çalışma Yılmaz (2014), 57 ülkeyi 1960 ve 2010 dönemi için OGT açısından incelemiştir. Çalışmanın sonuçlarına göre 57 ülkeden 28'i OGT'dir.

Tiftikçiğil, Güriş ve Yaşgül (2018) çalışması Robertson ve Ye (2013) yaklaşımının kullanıldığı diğer bir çalışmadır. Yazarlar, 1969- 2015 dönemi yıllık verileri kullanılarak E7 ülkelerinde orta gelir tuzağının varlığı araştırılmıştır. Çalışmada doğrusal, doğrusal olmayan, panel ve doğrusal olmayan panel birim kök testleri 
kullanılmıştır. Elde edilen bulgulara göre genel olarak E7 ülkelerinin orta gelir tuzağında olmadığı sonucuna ulaşılmıştır.

\section{Ekonometrik Metodoloji}

Çalışmada E7 ülkelerinin orta gelir tuzağında olup olmadığı birim kök testleri ile araştırılacaktır. Zaman serisi literatüründe birim kökün varlığını araștıran ilk test Dickey ve Fuller (DF) (1979) çalışmalarıyla ortaya koydukları testtir. Birinci mertebeden otoregresif süreçlere uygulanan Dickey ve Fuller (1979) testi, yüksek dereceden otoregresif süreçler için geliştirilmiş ve Genelleştirilmiş Dickey ve Fuller (ADF) (1981) testi adını almıştır. Phillips ve Perron (1988) çalışmalarında DF birim kök testini geliştirerek parametrik olmayan yeni bir test geliştirmişlerdir. DF ve ADF birim kök testleri hata terimlerinin birbirinden bağımsız ve sabit varyansa sahip olduğunu varsaymaktadır. Phillips ve Perron (1988) çalışmalarında bu varsayımı geliştirerek, hata terimleri arasında otokorelasyon olabileceğini ifade etmiş ve bu testlere yeni bir boyut kazandırmıştır.

Zaman serisi analizlerinde, iç ya da diş birçok sebepten ötürü değişkenlerin yapısında değişiklikler yaşanabilmektedir. Zaman serilerinde yaşanan bu değişiklikleri dikkate alan testlerin kullanılması elde edilen sonuçların güvenilirliği açısından önemlidir. İncelenen değişkenlerde yapısal kırılmaların varlığı durumunda klasik birim kök testlerinin kullanılması eğilimli ya da hatalı sonuçlar elde edilmesine sebep olabilecektir. Birim kök testleri literatüründe yapısal kırılmaların varlığını dikkate alan ilk test Perron (1989) testidir. Perron (1989) çalışmasıyla geliştirilen test dıșsal olarak belirlenen bir yapısal kırılmanın varlığına izin vermektedir. Perron (1989) çalışmasından sonra farklı özelliklere sahip daha gelişmiş yapısal kırılmalı birim kök testleri literatüre kazandırılmıştır. Çalışmanın kapsamı altında sırasıyla Zivot ve Andrews (1992), Lee ve Strazicich (2013), Lumsdaine ve Papell (1997) ve Lee ve Strazicich (2003) testleri anlatılacaktır.

Perron (1989) testi, dışsal olarak belirlenen bir yapısal kırılma altında üç model yapısı önermiştir. Bunlardan Model A 
düzeyde dışsal yapısal değişmeyi, Model B eğimdeki dışsal yapısal değișmeyi ve Model C düzeyde ve eğimdeki dışsal yapısal değişmeyi ifade etmektedir. Zivot ve Andrews (1992) çalışması, Perron (1989) testinde yapısal kırılmanın dışsal belirlenme durumunu eleştirmiş ve içsel olarak belirlenen bir yapisal kırılmanın varlığına izin veren test prosedürü önermişlerdir.

Zivot ve Andrews (1992) testinde, yapısal kırılma olmadan birim kökü ifade eden temel hipoteze karşı trend fonksiyonunda yapısal kırılmalı durağanlı̆̆ ifade eden alternatif hipotez sinanmaktadır. Zivot ve Andrews (1992), Perron testindeki ADF prosedürünü izleyerek aşağıdaki üç modeli (sırasıyla Model A, Model B ve Model C) geliştirmişlerdir.

$$
y_{t}=\hat{\mu}^{A}+\hat{\theta}^{A} D U_{t}(\hat{\lambda})+\hat{\beta}^{A} t+\hat{\alpha}^{A} y_{t-1}+\sum_{j=1}^{k} \hat{c}_{j}^{A} \Delta y_{t-j}+\hat{e}_{t}
$$

$$
y_{t}=\hat{\mu}^{B}+\hat{\beta}^{B} t+\hat{\gamma}^{B} D T_{t}^{*}(\hat{\lambda})+\hat{\alpha}^{B} y_{t-1}+\sum_{j=1}^{k} \hat{c}_{j}^{B} \Delta y_{t-j}+\hat{e}_{t}
$$

$$
y_{t}=\hat{\mu}^{C}+\hat{\theta}^{C} D U_{t}(\hat{\lambda})+\hat{\beta}^{C} t+\hat{\gamma}^{C} D T_{t}^{*}(\hat{\lambda})+\hat{\alpha}^{C} y_{t-1}+\sum_{j=1}^{k} \hat{c}_{j}^{C} \Delta y_{t-j}+\hat{e}_{t}
$$

Modelde yer alan $D U_{t}(\lambda), t>T \lambda$ için 1 diğer durumlarda 0 değerini alan gölge değişkeni, $D T_{t}^{*}(\lambda)$ ise $t>T \lambda$ için $t-T \lambda$ diğer durumlarda 0 değerini alan gölge değişkeni ifade etmektedir. Zivot ve Andrews (1992) testinde, (3), (4) ve (5) denklemlerinde en küçük kareler yöntemi kullanılarak $\lambda=T_{B} / T$ hesaplanmaktadır. Burada $T_{B}$ yapısal kırılma zamanını göstermektedir. Her üç model için tablo kritik değerleri çalışmada tablolaştırılmıştır.

Yapısal kırılmalı birim kök literatüründe tek kırılmanın varlığına izin veren bir diğer test Lee ve Strazicich (2013) 
tarafından önerilen testtir. Bu testte, tek yapısal kırılmanın yeri içsel olarak belirlenmektedir ve tek kırılmalı Lagrange Çarpanı (LM) birim kök testi olarak bilinmektedir. Lee ve Strazicich (2013) testinde, daha önce geliștirilen Lee ve Strazicich (2003) iki yapısal kırılmalı birim kök testi ile burada önerilen tek yapısal kırılmalı birim kök test prosedürü birleștirilerek, araștırmacıların daha doğru tespitler yapabilmesine olanak sunmaktadır. Lee ve Strazicich (2013) testinde, gözlemlenemeyen bileşenler modeline dayalı veri yaratma süreci aşağıdaki gibidir.

$$
Y_{t}=\delta^{\prime} Z_{t}+X_{t}, \quad X_{t}=\beta X_{t-1}+\varepsilon_{t}
$$

Denklemde $Z_{t}$ dişsal değişkenler vektörünü ifade etmektedir ve $\varepsilon_{t} \square$ iid $N\left(0, \sigma^{2}\right)$ 'dir. Lee ve Strazicich (2013) testi Zivot ve Andrews (1992) ve Lumsdaine ve Papell (1997) testlerinden farklı olarak temel ve alternatif hipotez altında yapısal kırılmaların varlığına izin vermektedir. Testte, yapısal kırılmalı birim kök temel hipotezine karşı yapısal kırılmalı durağanlık alternatif hipotezi sınanmaktadır. Lee ve Strazicich (2013) testi, düzeyde kırılmayı ifade eden Model A ve düzeyde ve eğimde kırılmayı ifade eden Model C olmak üzere iki model önermiştir. Burada Model A, $t \geq T_{B}+1$ için $D_{t}=1$, diğer durumlarda 0 olan gölge değişkeni göstermek üzere $Z_{t}=\left[1, t, D_{t}\right]$ ' ile ifade edilmektedir. $T_{B j}$, kırılmanın gerçekleştiği zaman periyodunu göstermektedir ve $\delta^{\prime}=\left(\delta_{1}, \delta_{2}, \delta_{3}\right)$ 'dir. Model C ise $t \geq T_{B}+1$ için $D T_{t}=t-T_{B}$, diğer durumlarda 0 olan gölge değişkeni göstermek üzere $Z_{t}=\left[1, t, D_{t}, D T_{t}\right]^{\prime}$ ile ifade edilmektedir.

Lee ve Strazicich (2013) testinde LM prosedürünü takiben birim kök test istatistiği aşağıdaki gibi elde edilebilmektedir.

$$
\Delta y_{t}=\delta^{\prime} \Delta Z_{t}+\phi \tilde{S}_{t-1}+u_{t}
$$


Denklemde $\tilde{S}_{t}=y_{t}-\tilde{\psi}_{x}-Z_{t} \tilde{\delta}, t=2, \ldots, T ; \tilde{\delta}, \Delta y_{t}{ }^{\prime} \operatorname{nin} \Delta Z_{t}$ üzerindeki regresyonundan elde edilen katsayılardır ve $\tilde{\psi}_{x}$, $y_{1}-Z_{1} \tilde{\delta}$ şeklinde elde edilebilmektedir. Testte, kırılmanın yeri $\left(T_{B}\right)$ tüm olası kırılmalar arasından minimum olan kırılma noktası (örneğin en negatif) birim kök testi $t$-istatistiği aşağıdaki gibidir.

$\operatorname{Inf} \tilde{\tau}(\tilde{\lambda})=\operatorname{Inf}_{\lambda} \tilde{\tau}(\lambda)$

Burada, $\lambda=T_{B} / T$ şeklinde hesaplanmaktadır. Lee ve Strazicich (2013) testinde tablo kritik değerleri Model A ve Model C için tablolaştırılmıştır.

İlgilenilen iktisadi zaman serisinde birden fazla yapısal değişimin bulunması durumunda tek kırılmalı birim kök testlerinin kullanılması bilgi kaybına ve hatalı sonuçlar elde edilmesine sebep olacaktır. Bu nedenle, yapısal kırılmalı birim kök literatüründe iki ve daha çok kırılmayı dikkate alan testler de geliştirilmiştir.

Lumsdaine ve Papell (1997) testi içsel olarak belirlenen iki yapısal kırılmaya izin veren birim kök testi olup, Zivot ve Andrews (1992) testinin genişletilmiş halidir. Lumsdaine ve Papell (1997) testinde, farklı bilinmeyen zamanlar için deterministik trendde iki kırılmaya izin veren testin istatistikleri tüm örneklem kullanılarak hesaplanabilmektedir. Bu model,

$\Delta y_{t}=\mu+\beta t+\theta D U 1_{t}+\gamma D T 1_{t}+\omega D U 2_{t}+\psi D T 2_{t}+\alpha y_{t-1}+\sum_{i=1}^{k} c_{i} \Delta y_{t-i}+\varepsilon_{t}$

şeklinde gösterilebilmektedir. Modelde, $D U 1_{t}$ ve $D U 2_{t}$ sirasiyla $T B 1$ ve $T B 2$ zamanlarında serinin ortalamasında meydana gelen kırılmalar için gölge değişkenleri ve $D T 1_{t}$ ve $D T 2_{t}$ ise trenddeki kırılmalar için kullanılan değişkenleri ifade etmektedir. TB1 ve $T B 2$ sırasıyla birinci ve ikinci kırılma zamanını göstermektedir. 
Modelde, $D U 1_{t}, t>T B 1$ için 1 diğer durumlarda 0 değerini alan gölge değişkeni, $D U 2_{t}, t>T B 2$ için 1 diğer durumlarda 0 değerini alan gölge değişkeni, $D T 1_{t}, t>T B 1$ için $t-T B 1$ diğer durumlarda 0 değerini alan gölge değişkeni ve $D T 2_{t}$ ise $t>T B 2$ için $t-T B 2$ diğer durumlarda 0 değerini alan gölge değişkeni ifade etmektedir.

Lumsdaine ve Papell (1997) testinde denklem (9) en geniş model olan düzeyde ve trendde iki yapısal kırılmaya izin veren Model CC'yi ifade etmektedir. Bu modelden DT1 ve DT2'nin çıkartılmasıyla düzeyde iki yapısal kırılmaya izin veren Model AA elde edilmektedir. Aynı modelden DT2'nin çıkartılmasıyla TB1 zamanında düzeyde ve eğimde bir kırılmaya ve $T B 2$ zamanında düzeyde kırılmaya izin veren Model CA elde edilmektedir. Lumsdaine ve Papell (1997) testinde yapısal kırılmasız birim kökün varlığını ifade eden temel hipoteze karşı iki yapısal kırılma altında trend durağan olduğunu ifade eden alternatif hipotez sinanabilmektedir.

Yapısal kırılmalı birim kök literatürünün önemli testlerinden biri Lee ve Strazicich (2003) testidir. Lee ve Strazicich (2003) testi, içsel olarak belirlenen iki yapısal kırılmayı dikkate almaktadır. Test, LM testi olarak da adlandırılmakta olup, teste ait regresyon,

$y_{t}=\delta^{\prime} Z_{t}+e_{t}$

$$
e_{t}=\beta e_{t-1}+\varepsilon_{t}
$$

şeklinde gösterilmektedir. Regresyonda $Z_{t}$ dışsal değişkenler vektörünü ifade etmektedir ve $\varepsilon_{t} \square$ iid $N\left(0, \sigma^{2}\right)$ 'dir. Lee ve Strazicich (2003) testinde Model A düzeyde iki kırılmaya izin veren modeldir ve $Z_{t}=\left[1, t, D_{1 t}, D_{2, t}\right]^{\prime}$ olarak tanımlanabilmektedir. Model $\mathrm{C}$ ise düzeyde ve trendde iki yapısal kırılmaya izin vermekte ve $Z_{t}=\left[1, t, D_{1 t}, D_{2, t}, D T_{1 t}, D T_{2, t}\right]^{\prime}$ şeklinde ifade edilebilmektedir. Lagrange Çarpanı prensibini takiben iki kırılmalı LM birim kök test istatistiği aşağıdaki regresyondan tahmin edilmektedir: 
$\Delta y_{t}=\delta^{\prime} \Delta Z_{t}+\phi \tilde{S}_{t-1}+u_{t}$

Burada $\tilde{S}_{t}=y_{t}-\tilde{\psi}_{x}-Z_{t} \tilde{\delta}, t=2, \ldots, T^{\prime}$ 'dir. İçsel iki kırılma için LM test istatistikleri $\tilde{\rho}=T \tilde{\phi}$ ve $\tilde{\tau}=$ temel hipotez $\phi=0$ test eden test $\mathrm{t}$ istatistiği şeklindedir. LM birim kök testinde $T_{B j}$ içsel olarak belirlenen kırılma noktalarını ifade etmek üzere ızgara tarama yöntemiyle test istatistiğinin minimum olduğu noktalarda aşağıdaki gibi aranmaktadır:

$$
L M_{\tau}=\inf _{\lambda} \tilde{\tau}(\lambda)
$$

Testte, Lee ve Strazicich (2013) tek yapısal kırılmalı birim kök testinde olduğu gibi temel ve alternatif hipotezde yapısal kırılmalar dikkate alınmaktadır. Yani, yapısal kırılmalar altında birim kökün varlı̆̆ını gösteren temel hipoteze karşı iki yapısal kırılma altında durağanlığı gösteren alternatif hipotez sınanmaktadır. Lee ve Strazicich (2003) çalışmasında, ilgili model için tablo kritik değerleri elde edilmiş ve tablolaştırılmıştır.

\section{Veri ve Uygulama Sonuçları}

Çalışmada E7 ülkelerinin (Brazilya, Çin, Hindistan, Endonezya, Meksika, Rusya ve Türkiye) orta gelir tuzağında olup olmadıkları Robertson ve Ye (2013) yaklaşımı dikkate alınarak klasik birim kök testleri ve yapısal kırılmalı birim kök testleri ile araștırılacaktır. Çalışmada Brezilya, Çin, Hindistan, Endonezya, Meksika ve Türkiye için 1960- 2016 dönemi, Rusya için 1989-2016 dönemi yıllık kişi başına GSYIH verileri doğal logaritmik formda kullanılmıştır. Gelişmiş merkez ülke olarak ABD verisi kullanılmıştır. Analizde kullanılan veriler World Development Indicators (WDI) veri tabanından elde edilmiştir. E7 ülkelerinde orta gelir tuzağının geçerliliği Robertson ve Ye (2013) yaklaşımı çerçevesinde klasik birim kök testleri ile analiz edilmiş ve Tablo 1 'de tablolaştırılmıştır. 
Tablo 1: ADF ve PP Birim Kök Testi Sonuçları

\begin{tabular}{lcccccl} 
Ülkeler & \multicolumn{2}{c}{ ADF sbt. } & \multicolumn{2}{c}{ ADF sbt.+Tr. } & PP Sbt. & PP Sbt.+Tr. \\
& $L$ & Test İst. & $L$ & Test İst. & Test İst. & Test İst. \\
\hline Brezilya & 2 & -2.2990 & 2 & -2.2942 & -1.8025 & -1.7839 \\
Çin & 2 & -2.3392 & 3 & -2.2288 & -2.3332 & $-4.2354 * * *$ \\
Hindistan & 0 & 3.1243 & 0 & 0.0212 & 2.5956 & 0.6078 \\
Endonezya & 1 & -0.1274 & 1 & $-3.9447 * *$ & -0.2642 & $-3.2792^{*}$ \\
Meksika & 1 & -1.4346 & 1 & -2.5544 & -1.0857 & -2.1514 \\
Rusya & 6 & $-3.8655^{* * *}$ & 6 & $-3.5526^{*}$ & $-3.5058^{* *}$ & -2.3709 \\
Türkiye & 0 & 0.5276 & 0 & -0.7927 & 0.4685 & -0.8646 \\
\hline
\end{tabular}

Not: Tabloda $L$ uygun gecikme uzunluğunu, Sbt. sabitli yapıyı ve Sbt.+Tr. ise sabitli ve trendli yapıyı ifade etmektedir. ${ }^{* * *}$ ve ${ }^{* * *}$ sırasıyla $\% 10, \% 5$ ve $\% 1$ için birim kök temel hipotezinin reddedildiğini göstermektedir. Gecikme uzunluğunun belirlenmesinde Akaike kriteri kullanılmıştır. Testlere ait kritik değerler MacKinnon (1996) çalışmasına dayanmaktadır.

Tablo 1'de yer alan ADF birim kök testi sonucuna göre sabitli model yapısı için Rusya hariç diğer ülkelerde birim kök temel hipotezi reddedilememiştir. ADF testi trendli ve sabitli model yapı için uygulama sonuçlarına göre Endonezya ve Rusya haricindeki tüm ülkelerde birim kök temel hipotezi reddedilememiştir. PP testi sabitli yapı için Rusya hariç diğer ülkelerde birim kök temel hipotezi reddedilememektedir. Aynı testin trendli ve sabitli yapısı için sonuçlara bakıldığında Çin ve Endonezya'da birim kök temel hipotezinin reddedildiği görülmektedir. Klasik birim kök testleri sonuçlarına göre Robertson ve Ye (2013) yaklaşımı çerçevesinde genel olarak Endonezya ve Rusya'nın orta gelir tuzağında olduğu söylenebilir.

Tablo 2: Tek Yapısal Kırılmalı Birim Kök Test Sonuçları

\begin{tabular}{|c|c|c|c|c|c|c|c|c|c|c|c|c|}
\hline \multirow{3}{*}{ Ülkeler } & \multirow{2}{*}{\multicolumn{3}{|c|}{ ZA Model A }} & \multirow{2}{*}{\multicolumn{3}{|c|}{$\begin{array}{l}\text { ZA Model C } \\
\text { Test }\end{array}$}} & \multirow{2}{*}{\multicolumn{3}{|c|}{$\begin{array}{l}\text { LS Model A } \\
\text { Test }\end{array}$}} & & & \\
\hline & & & & & & & & & & \multicolumn{3}{|c|}{ LS Model C } \\
\hline & $L$ & Test İst. & $\mathrm{TB}$ & $L$ & İst. & $\mathrm{TB}$ & $L$ & İst. & $\mathrm{TB}$ & $L$ & Test İst. & $\mathrm{TB}$ \\
\hline \multirow[t]{2}{*}{ Brezilya } & & & & & & 198 & & $\begin{array}{l}- \\
2.856\end{array}$ & 198 & & & 197 \\
\hline & 1 & -3.5346 & 1971 & 2 & -4.6956 & 1 & 2 & 7 & 4 & 2 & -3.4800 & 9 \\
\hline 352 & & & & & & & & $\begin{array}{r}\text { Akad } \\
\text { Cilt }\end{array}$ & $\begin{array}{l}\text { aik } \\
3-\end{array}$ & & $\begin{array}{l}\text { emeler D } \\
2 \text { (Ekim }\end{array}$ & $\begin{array}{l}\text { ergisi } \\
\text { 2018) }\end{array}$ \\
\hline
\end{tabular}




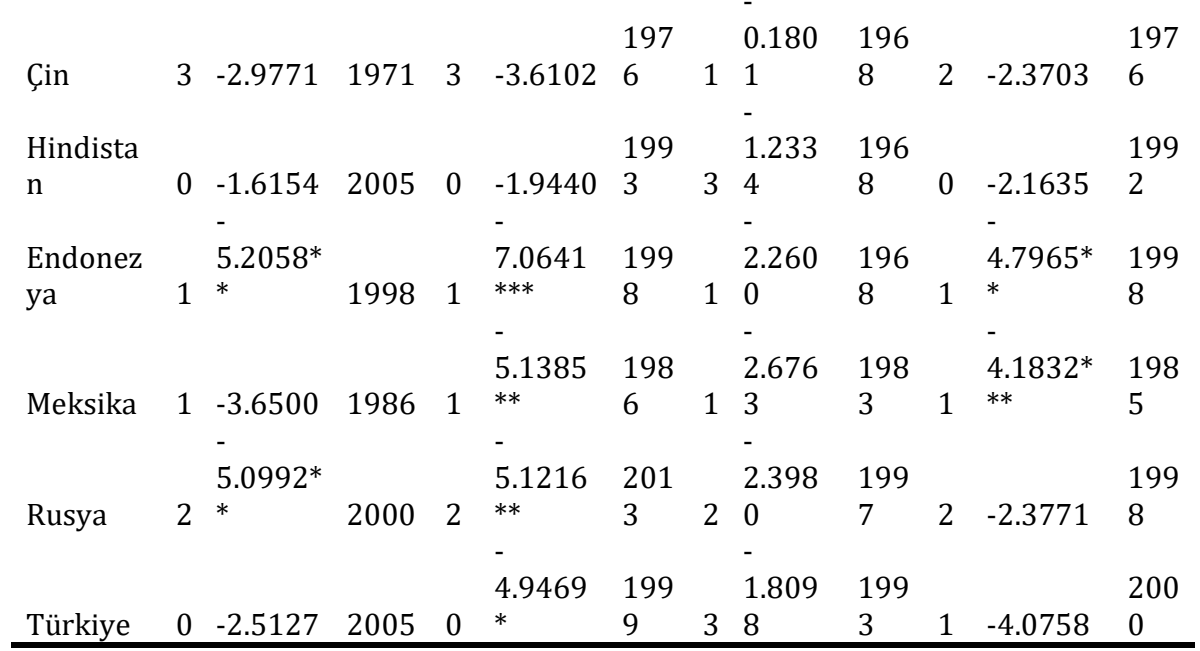

Not: Tabloda $L$ uygun gecikme uzunluğunu ve TB kırılma tarihini ifade etmektedir. ${ }^{* * *}$ ve ${ }^{* * *}$ sirasılyla $\% 10, \% 5$ ve $\% 1$ için birim kök temel hipotezinin reddedildiğini göstermektedir. ZA (1992) testinde, gecikme uzunluğunun belirlenmesinde Akaike kriteri, LS (2013) testinde genelden özele yaklaşımı kullanılmıștır. ZA (1992) testi ve LS (2013) testi kritik değerleri sırasılyla Zivot ve Andrews (1992) ve Lee ve Strazicich (2013) çalışmalarından elde edilmiştir.

Tablo 2'de tek yapısal kırılmaya izin veren birim kök testlerinden Zivot ve Andrews (1992) ve Lee ve Strazicich (2013) test sonuçları yer almaktadır. Elde edilen bulgulara göre, Zivot ve Andrews (1992) testinde Endonezya, Meksika, Rusya ve Türkiye'de birim kök temel hipotezi reddedilmiştir. Lee ve Strazizich (2013) testinde ise Model C için sadece Endonezya ve Meksika'da birim kök temel hipotezi reddedilmiștir. Tek yapısal kırılmalı birim kök testi sonuçlarına göre genel olarak Endonezya, Meksika ve Rusya'nın durağan özellik sergilediği belirlenmiștir.

Tablo 3: İki Yapısal Kırılmalı Birim Kök Test Sonuçları

\begin{tabular}{lllllllll} 
Ülkeler & \multicolumn{4}{c}{ LP Model AA } & \multicolumn{4}{c}{ LP Model CC } \\
& $L$ & Test İst. & TB1 & TB2 & $L$ & Test İst. & TB1 & TB2 \\
\hline Brezilya & 2 & -4.5125 & 1970 & 2006 & 2 & -5.5616 & 1978 & 1997 \\
Çin & 3 & -3.688 & 1975 & 2005 & 3 & -5.2246 & 1975 & 2006 \\
Hindistan & 0 & -2.5227 & 1970 & 2005 & 0 & -4.7464 & 1978 & 1999
\end{tabular}

Journal of Academic Inquiries 353

Volume 13 - Issue 2 (October 2018) 


\begin{tabular}{|c|c|c|c|c|c|c|c|c|}
\hline Endonezya & 1 & $-6.8020 * * *$ & 1997 & 2007 & 1 & $-7.6261 * * *$ & 1984 & 1997 \\
\hline Meksika & 1 & -5.2932 & 1977 & 1985 & 1 & -6.0332 & 1985 & 2000 \\
\hline Rusya & 2 & $-6.2028 * *$ & 1999 & 2005 & 2 & $-6.6627^{*}$ & 1997 & 2009 \\
\hline Türkiye & 0 & -3.9722 & 1997 & 2009 & 0 & -6.4175 & 1978 & 1998 \\
\hline \multirow{2}{*}{ Ülkeler } & \multicolumn{4}{|c|}{ LS Model A } & \multicolumn{4}{|c|}{ LS Model C } \\
\hline & $L$ & Test İst. & TB1 & TB2 & $L$ & Test İst. & TB1 & TB2 \\
\hline Brezilya & 2 & -3.3428 & 1979 & 1984 & 3 & -4.4907 & 1979 & 1998 \\
\hline Çin & 1 & -0.3268 & 1968 & 1982 & 1 & -4.6448 & 1968 & 1980 \\
\hline Hindistan & 3 & -1.4447 & 1968 & 1974 & 1 & -4.7398 & 1982 & 2005 \\
\hline Endonezya & 3 & -2.6821 & 1994 & 2000 & 1 & -4.1203 & 1972 & 1998 \\
\hline Meksika & 1 & $-3.6781 *$ & 1983 & 1994 & 1 & $-5.8896 * *$ & 1978 & 1985 \\
\hline Rusya & 2 & -2.9521 & 1997 & 2008 & 2 & $-8.6510^{* * *}$ & 1998 & 2008 \\
\hline Türkiye & 0 & -2.0242 & 2003 & 2010 & 1 & -4.948 & 1988 & 2000 \\
\hline
\end{tabular}

Not: Tabloda $L$ uygun gecikme uzunluğunu, TB1 ve TB2 sırasıyla birinci ve ikinci kırılma tarihini ifade etmektedir. ${ }^{* * *}$ ve ${ }^{* * *}$ sırasıyla $\% 10, \% 5$ ve $\% 1$ için birim kök temel hipotezinin reddedildiğini göstermektedir. LP (1997) ve LS (2003) testinde gecikme uzunluğunun belirlenmesinde genelden özele yaklaşımı kullanılmıştır. LP (1997) testi ve LS (2003) testi kritik değerleri sırasıyla BenDavid, Lumsdaine ve Papell (2003) ve Lee ve Strazicich (2003) çalışmalarından elde edilmiştir.

Tablo 3'de ise iki yapısal kırılmaya izin veren birim kök testleri yer almaktadır. Tablonun ilk bölümünde Lumsdaine ve Papell (1997) testi, ikinci bölümünde Lee ve Strazicich (2003) test sonuçları görülmektedir. Lumsdaine ve Papell (1997) testi Model AA ve Model CC için sadece Endonezya ve Rusya'da birim kök temel hipotezinin reddedildiğini göstermiştir. Lee ve Strazicich (2003) testi ise bu iki model yapısı için Meksika ve Rusya'da birim kök temel hipotezinin reddedildiğini göstermiștir. İki yapısal kırılma altında genel olarak Endonezya, Meksika ve Rusya'nın orta gelir tuzağında olduğu sonucuna ulaşılmıştır.

Yapılan ampirik çalışma sonucunda genel olarak değerlendirmek gerekirse Robertson ve Ye (2013) yaklaşımı dikkate alındığında E7 ülke grubunu oluşturan ülkelerden Endonezya, Meksika ve Rusya'nın orta gelir tuzağında olduğu 
yönünde kanıtlara ulaşılmıştır. Benzer şekilde aynı yaklaşım dikkate alındığında E7 ülke grubunu oluşturan diğer ülkeler Brezilya, Çin, Hindistan ve Türkiye'nin ise genel olarak orta gelir tuzağında olmadığı bulgularına ulaşılmıştır. Literatür incelendiğinde E7 ülkeleri için orta gelir tuzağını araştıran Tiftikçiğil, Güriş ve Yaşgül (2018) çalışması ile Brezilya ve Endonezya'da farklı, Çin, Meksika, Hindistan ve Türkiye'de aynı sonuca ulaşılmıştır. 71 orta gelirli ülke için orta gelir tuzağını araștıran Ünlü ve Yıldız (2018) çalışması ile Brezilya ve Çin'de farklı, Endonezya, Meksika, Hindistan ve Türkiye'de aynı sonuca ulaşılmıştır. Türkiye için değerlendirmek gerekirse, Robertson ve Ye (2013) çerçevesinde Koçak ve Bulut (2014), Tiftikçiğil, Güriş ve Yaşgül (2018), Ünlü ve Yıldız (2018) ve çalışmamızda orta gelir tuzağında olmayacağı belirlenmiştir.

Robertson ve Ye (2013) yaklaşımı altında, Brezilya, Çin, Hindistan ve Türkiye ekonomisinin, merkez ülke olarak seçilen ABD ekonomisi ile arasındaki gelir farkını kapatma eğilimi, Endonezya, Meksika ve Rusya ekonomisinin ise gelir farkını kapatmama eğilimi göstermiştir. Orta gelir tuzağında bulunan ülkelerde genel olarak tasarruflar ve yatırımlar düşük seviyede kalmakta, sanayide çeşitlenme olmamakta ve büyümede yavaşlama görülmektedir. Orta gelir tuzağında bulunan ülkelerin tuzaktan kurtulmak için öncelikle; makroekonomik istikrarı sağlaması, gelir eşitsizliklerini gidermesi, ulusal tasarruf oranlarını arttırılması, Araştırma-Geliştirme yatırımlarını arttırması, işgücü piyasası reformlarını arttırması, mali sürdürülebilirliği sağlaması, altyapı yatırımlarını arttırması, finansal piyasaların etkinliğini arttıracak politikaların izlenmesi, inovasyon kapasitesinin arttırılması, mülkiyet haklarının korunması ve toplam faktör verimliliğinin arttırılması gerekmektedir.

\section{Sonuç ve Değerlendirme}

Orta gelir tuzağı son dönemlerde araștırmacıların ilgisini çeken ve iktisat literatürünün yeni konularından bir olduğu söylenebilir. Zira ilk kez 2007 yılında, Dünya Bankasının bir raporu olan "Bir Doğu Asya Rönesans'ı: Ekonomik Büyüme için Fikirler" 
başlıklı çalışmayla literatüre kazandırılan orta gelir tuzağı olgusu, özellikle alt ve üst orta gelir grubu için önemli bir kavram haline gelmiştir. Bu raporda, orta gelir seviyesine ulaşmış bazı ülkelerin, uzun süre boyunca, kendilerinden daha düşük gelir grubundaki ülkeler ile ücret bakımından rekabet edememesi ve kendilerinden daha yüksek gelir grubundaki ülkeler karşısında ise inovasyona yönelik büyüme stratejileri gerçekleştirememelerinden dolayı düşük büyüme performansı gerçekleştirerek orta gelir tuzağına yakalandıklarından bahsedilmiştir.

Bu çalışmada, orta gelir tuzağına nispi eşik değerler ile uygun bir șekilde OGT'nin zaman serisi tanımını geliştiren Robertson ve Ye (2013)'ün yaklaşımı kullanılarak E7 ülkeleri (Brezilya, Çin, Hindistan, Endonezya, Meksika, Rusya ve Türkiye) için OGT araştırılmıştır. Yapılan ampirik analizler Brezilya, Çin, Hindistan, Endonezya, Meksika ve Türkiye için 1960- 2016 dönemi, Rusya için 1989- 2016 dönemi yıllık verileri kullanılarak klasik ve yapısal kırılmalı birim kök testleri ile gerçekleştirilmiştir. Elde edilen bulgulara göre, Robertson ve Ye (2013) yaklaşımı çerçevesinde tüm durumlarda olmasa da genel olarak Endonezya, Meksika ve Rusya'nın orta gelir tuzağında olduğu yönünde kanıtlara ulaşılmıștır. Analize konu diğer ülkeler Brezilya, Çin, Hindistan ve Türkiye'nin ise genel olarak orta gelir tuzağında olmadığı sonucuna varılmıştır. Elde edilen bu sonuçlar, E7 ülkeleri üzerine incelemede bulunan Tiftikçiğil, Güriş ve Yaşgül (2018) çalışması ile iki ülke için farklı, dört ülke için aynı sonuca ulaşıldığını, benzer şekilde Ünlü ve Yıldız (2018) çalışması ile iki ülke için farklı, dört ülke için aynı sonuca ulaşıldığını göstermiştir. Farklılıkların sebebi olarak, incelenen dönemin aynı olmaması ve ampirik analizde kullanılan testlerin tamamen farklı olası gösterilebilir.

Gelişmekte olan ülkeler arasında önemli bir yere sahip E7 ülke grubunu oluşturan Brezilya, Çin, Hindistan ve Türkiye ekonomisinin, merkez ülke olarak seçilen ABD ekonomisi ile arasındaki gelir farkını, analiz dönemi olan 1960-2016 yılları arasında kapatma eğilimi göstermiştir. Endonezya, Meksika ve Rusya ekonomilerinin ise bu farkı kapatamama eğiliminin olduğu sonucuna ulaşılmıştır. Endonezya, Meksika ve Rusya'nın orta gelir 
tuzağından kurtulmak için öncelikle; makroekonomik istikrarı sağlaması, gelir eşitsizliklerini gidermesi, ulusal tasarruf oranlarını arttırılması, Araştırma-Geliștirme yatırımlarını arttırması ve işgücü piyasası reformlarını arttırması gerekmektedir. Bunlarla birlikte orta gelir tuzağından çıkmak için; enerji bağımlılığının azaltılması, altyapı yatırımlarının arttırılması, bölgesel farklılıkların azaltılmaya çalışılması, mülkiyet haklarının korunmasına yönelik çalışmaların yapılması önemle üzerinde durulması gereken diğer kriterlerdir. Orta gelir tuzağında bulunmayan ülkelerin de yüksek gelir grubuna ulaşana kadar bu konulara dikkat etmesi, kalıcı büyümenin sağlanması ve orta gelir tuzağına düşülmemesi adına gerekli olduğu söylenebilir. 


\section{Kaynakça}

Agénor, P., Canuto, O., \& Jelenic, M. (2012). Avoiding Middle-Income Growth Traps, (Number: 98). Washington, DC: The World Bank.

Agénor, P., \& Canuto, O. (2015). Middle-Income Growth Traps. Research in Economics, 69(4), 641-660.

Aiyar, M. S., Duval, M. R. A., Puy, M. D., Wu, M. Y., \& Zhang, M. L. (2013). Growth Slowdowns and the Middle-Income Trap, (Working Paper / 13 / 71). Washington, DC: International Monetary Fund.

Ben-David, D., Lumsdaine, R.L. \& Papell, D.H. (2003). Unit Roots, Postwar Slowdowns and Long-Run Growth: Evidence from Two Structural Breaks. Empirical Economics, 28(2), 303-319.

Bozkurt, E., Bedir, S., Özdemir, D., \& Çakmak, E. (2014). Orta Gelir Tuzağı ve Türkiye Örneği. Maliye Dergisi, 167, 22-39.

Bulman, D., Eden, M., \& Nguyen, H. (2014). Transitioning from LowIncome Growth to High- Income Growth: Is There a Middle Income Trap, (Policy Research Working Paper 7104). Washington, DC: The World Bank.

Dalgıç, B., İyidogan, P., \& Balıkçıoğlu, E. (2014). Orta Gelir Tuzağından Çıkışta Hangi Faktörler?. Maliye Dergisi, 167, 116-125.

Dickey, D., \& Fuller W. (1979). Distribution of The Estimators for Autoregressive Time Series with A Unit Root. Journal of the American Statistical Association, 74, 427-431.

Dickey, D. and Fuller W. (1981). Likelihood Ratio Statistics for Autoregressive Time Series with A Unit Root. Econometrica, 49(4), 1057-1072. 
Egawa, A. (2013). Will Income Inequality Cause a Middle-income Trap in Asia? (Bruegel Working Paper 2013/06). Brussel: Bruegel.

Eichengreen, B., Park, D., \& Shin, K. (2012). When Fast-Growing Economies Slow Down: International Evidence and Implications for China. Asian Economic Papers, 11(1), $42-87$.

Felipe, J., Abdon, A., \& Kumar, U. (2012). Tracking the Middleincome Trap: What Is It, Who Is in It, and Why? (Working Paper No. 715). New York: Levy Economics Institute.

Gill, I. S., Kharas, H. J., \& Bhattasali, D. (2007). An East Asian renaissance: ideas for economic growth. World Bank Publications.

Gill, I., \& Kharas, H. (2015). "The Middle-Incime Trap Turns Ten". World Bank Policy Research Working Paper 7403:1-27.

Im, F. G., \& Rosenblatt, D. (2013). Middle-Income Traps: A Conceptual and Empirical Survey, (Policy Research Working Paper 6594). Washington, DC: The World Bank.

Jankowska, A., Nagengast, A., \& Perea, J. R. (2012). The Product Space and the Middleincome Trap: Comparing Asian and Latin American Experiences, (Working Paper No. 311). Paris: OECD Development Center.

Koçak, E., \& Bulut, Ü. (2014). Orta Gelir Tuzağı: Teorik Çerçeve, Ampirik Yaklaşımlar ve Türkiye Üzerine Ekonometrik Bir Uygulama. Maliye Dergisi, 167, 1-21.

Lee, J., \& Strazicich, M. C. (2003). Minimum Lagrange Multiplier Unit Root Test with Two Structural Breaks. The Review of Economcis and Statistics, 85(4), 1082-1089.

Lee, J., \& Strazicich, M. C. (2013). Minimum LM Unit Root Test with One Structural Break. Economics Bulletin, 33(4), 2483-2492. 
Lumsdaine, R. L. \& Papell, D. H. (1997). Multiple Trends Breaks and the Unit-Root Hypothesis. The Review of Economics and Statistics, 79(2), 212-218.

MacKinnon, J. G. (1996). Numerical Distribution Functions for Unit Root and Cointegration Tests. Journal of Applied Econometrics, 11, 601-618.

Maddison, A. (2010). Statistics on World Population, GDP and Per Capita GDP, 1-2008 AD,Available at: http://www.ggdc.net/MADDISON/oriindex.htm (data accessed on 03/01/2018).

Perron, P. (1989). The Great Cash, The Oil Price Shock and The Unit Root Hypothesis, Econometrica, 57(6), 1361-1401.

Robertson, P. E., \& Ye, L. (2013). On the Existence of a Middle Income Trap, (Economics Discussion Paper 13.12). Perth: University of Western Australia.

Tiftikçiğil, B. Y., Güriş, B., \& Yaşgül, Y. S. (2018). Does Middle Income Trap Exist? Evidence from Emerging Economies: E7 Countries 1969-2015. Revista Galega de Economia, 27(1), 145-162.

Tho, T. (2013). The Middle-Income Trap. Issues for Members of the Association of Southeast Asian Nations. VNU Journal of Economics and Business, 29(2), 107-128.

Ünlü, F. ve Yıldız, R. (2018). Orta Gelir Tuzağının Belirlenmesi: Ekonometrik Analiz. Uluslararası Yönetim Íktisat ve Issletme Dergisi, 14(1), 1-20.

Woo, T. W. (2012). China Meets the Middle-Income Trap: The Large Potholes in the Road to Catching-up. Journal of Chinese Economic and Business Studies, 10(4), 313-336.

Yeldan, E. (2012). Türkiye Orta Gelir Tuzağına Yaklaşırken. İktisat ve Toplum, 21-22, 26-30. 
Yıldız, F., \& Bayraktar, Y. (2017). Kırılgan Sekizli Ülkelerinin Orta Gelir Tuzağına Uzaklığının Ölçülmesi: Karşılaştırmalı Bir Analiz. Kırklareli Üniversitesi Íktisadi ve İdari Bilimler Fakültesi Dergisi, 6(5), 110-128.

Yılmaz, G. (2014). Turkish Middle Income Trap and Less Skilled Human Capital, (Working Paper No: 14/30). Ankara: Central Bank of the Republic of Turkey.

Zeng, J., \& Fang, Y. (2014). "Between Poverty and Prosperity: China's Dependent Development and the 'Middle-Income Trap'”. Third World Quarterly, 35(6), 1014-1031.

Zivot, E. \& Andrews, D. W. K. (1992). Further Evidence on the Great Crash, the Oil-Price Shock, and the Unit-Root Hypothesis. Journal of Business \& Economic Statistics, 10(3), 25-44. 